\title{
Higher urinary nitrate was associated with lower prevalence of congestive heart failure: results from NHANES
}

Zhuo $\mathrm{Wu}^{1 \dagger}$, Ting Tian ${ }^{2 \dagger}$, Wang Ma ${ }^{1 *} \mathbb{0}$, Wen Gao ${ }^{1 *}$ and Ninghong Song ${ }^{1 *}$

\begin{abstract}
Background: Some studies have reported that nitrate intake from vegetables was inversely associated with many vascular diseases, but few studies have paid attention to the relationship between urinary nitrate and cardiovascular diseases (CVDs). This cross-sectional study aimed to explore the connections between urinary nitrate and prevalence of CVDs.

Methods: The data of this study was collected from National Health and Nutrition Examination Survey (NHANES). Finally, several years' data of NHANES were merged into 14,894 observations. Logistic regression models were used to examine the associations between urinary nitrate and CVDs by using the "survey" package in R software (version 3.2.3).

Results: In the univariable logistic analysis, significant association was discovered between urinary nitrate and congestive heart failure, coronary heart disease, angina pectoris, myocardial infarction (all $P<0.001$ ). By adjusting related covariates, the multivariable logistic analysis showed that the significant association only existed between urinary nitrate and congestive heart failure $(\mathrm{OR}=0.651,95 \% \mathrm{Cl} 0.507-0.838, P<0.001)$. Compared to $\mathrm{Q} 1$ urinary nitrate level as reference, the risk for prevalent heart failure diminished along with increasing levels of urinary nitrates, (OR of Q2 level $=0.633,95 \% \mathrm{Cl} 0.403-0.994)$, (OR of Q3 level $=0.425,95 \% \mathrm{Cl} 0.230-0.783)$, (OR of Q4 level $=0.375,95 \% \mathrm{Cl}$ $0.210-0.661$ ), respectively. Moreover, urinary nitrate levels were associated with congestive heart failure in a dosedependent manner in both 20-60 years group, 60+ years group and male, female group $(P<0.001, P=0.011$ and $P=0.009, P=0.004$ ).
\end{abstract}

Conclusions: Independent of related covariates, higher urinary nitrate was associated with lower prevalent congestive heart failure.

Keywords: Urinary nitrate, Cardiovascular diseases, Congestive heart failure, Logistic regression model, Complex sample, NHANES

*Correspondence: 1300357846@qq.com; yoghurt831030@126.com; songninghong@126.com

'Zhuo Wu and Ting Tian contributed equally to this work and should be regarded as joint first authors

${ }^{1}$ The First Affiliated Hospital of Nanjing Medical University, Jiangsu

Province Hospital, Nanjing 210029, Jiangsu, China

Full list of author information is available at the end of the article

\section{Background}

In the past, nitrate was considered to be associated with detrimental health outcomes such as cancer [1, 2], however, understanding of the health impact of nitrate has recently undergone radical changes. In recent years, many researchers implemented studies on the relationship between dietary nitrate and vascular health [1-4]. It has been found that a short-term increase in nitrate intake can lower blood pressure [2] and improve endothelial function [4]. The circulation nitrate in 
human body mainly originate from two ways: oxidation of endogenously produced nitric oxide (NO) and our diet [5]. Dietary nitrate, abundant in beetroot and green leafy vegetables, is a potential and important alternative source for the production of NO via the nitrate-nitriteNO pathway [6]. Nitrate from diet is rapidly absorbed in the small intestine and approximately $75 \%$ will ultimately be excreted in the urine $[7,8]$. Thus, urinary nitrate can better reflect the level of nitrate in human body.

Cardiovascular diseases (CVDs) is the leading cause of death for entire population around the world [9]. Many studies have reported and demonstrated that increased dietary nitrate intake can decrease the risk of vascular diseases [10-13]. As is well known that endothelial dysfunction, especially impaired endothelium-dependent vasodilation mediated by $\mathrm{NO}$, is a crucial early event in the development of CVDs [14]. However, up to now, few studies figured out the relationship between urinary nitrate and CVDs. Therefore, we tried to explore in the study.

\section{Methods}

\section{Data source and study population}

The National Health and Nutrition Examination Survey (NHANES) is an ongoing cross-sectional monitoring survey of the non-institutionalized US civilians, which were managed by the US National Center for Health Statistics (Centers for Disease Control and Prevention, Atlanta, GA, USA) [15]. It was conducted by complex survey design including oversampling, survey non-response, and post-stratification, thus selecting a representative US sample. The survey examines a nationally representative sample of about 5000 persons each year. These persons are located in counties across the country, 15 of which are visited each year. Sample weights were set uniquely for each participant for accounting the complex survey design in NHANES. Physical examinations, clinical laboratory examinations, and related measurement procedures were collected by Mobile Examination Center. This cross-sectional study data was collected from 5 surveys (2001-2002, 2005-2006, 2007-2008, 2009-2010 and 2011-2012). Besides, participants with missing information of CVDs and urinary nitrate were excluded in this study. Then demography, hypercholesterolemia, diabetes, hypertension, BMI and cotinine information of each subjects were extracted. All the data were finally merged into totally 14,894 observations. Details were shown on Fig. 1.

\section{Urinary nitrate measurement}

Nitrate were measured in all available urine samples from $1 / 3$ subsets of study participants aged over 6 years old in NHANES 2001-2002, 2009-2010 and 2011-2012. In 2005-2006 and 2007-2008 NHANES, nitrate was tested in participants aged over 6 years old. Urine specimens for urinary nitrate testing were processed, stored, and transferred to the Division of Environmental Health Laboratory Sciences, National Center for Environmental Health, and Centers for Disease Control and Prevention. All details for the urine specimen collection and processing were elucidated in the NHANES LPM (NHANES Laboratory/Medical Technologists Procedures Manual). All samples were stored at $-20^{\circ} \mathrm{C}$ before being transported to National Center for Environmental Health for testing. Samples were analyzed for nitrate by using ion chromatography tandem mass spectrometry [16]. The NHANES kept to the quality assurance and quality control (QA) QC) protocols which met the 1988 Clinical Laboratory Improvement Act mandates. Details can been in the NHANES LPM.

\section{Cardiovascular diseases}

In NHANES, the CVDs were provided by a self-reported personal interview. Among the tested participants who needed to answer the CVDs conditions were all over 20 years old. Participants would be considered to have CVDs including congestive heart failure, coronary heart disease, angina and myocardial infarction if they confirmed yes to the questions "Has a doctor or other health professional ever told you that you had congestive heart failure?", "Has a doctor or other health professional ever told you that you had coronary heart disease?", "Has a doctor or other health professional ever told you that you had angina, also called angina pectoris?", "Has a doctor or other health professional ever told you that you had a heart attack (also called myocardial infarction)?" respectively. These questions were included in the medical conditions part of the interview survey, and the diseases condition of participants were based on the medical history diagnosed by the clinicians or medical institutions. Besides, the explanations in the manuals described these diseases condition and differences which can make it easier for the interviewer and participants to understand, and we displayed them as followings.

Congestive heart failure Is when the heart can't pump enough blood to the body. Blood and fluid "back up" into the lungs, which makes you short of breath. Heart failure causes fluid buildup in and swelling of the feet, legs and ankles.

Interviewer Do not count heart murmurs, irregular heart beats, chest pain or heart attacks.

Coronary heart disease Is when the blood vessels that bring blood to the heart muscle become narrow and hardened due to plaque (plak). Plaque buildup is called 


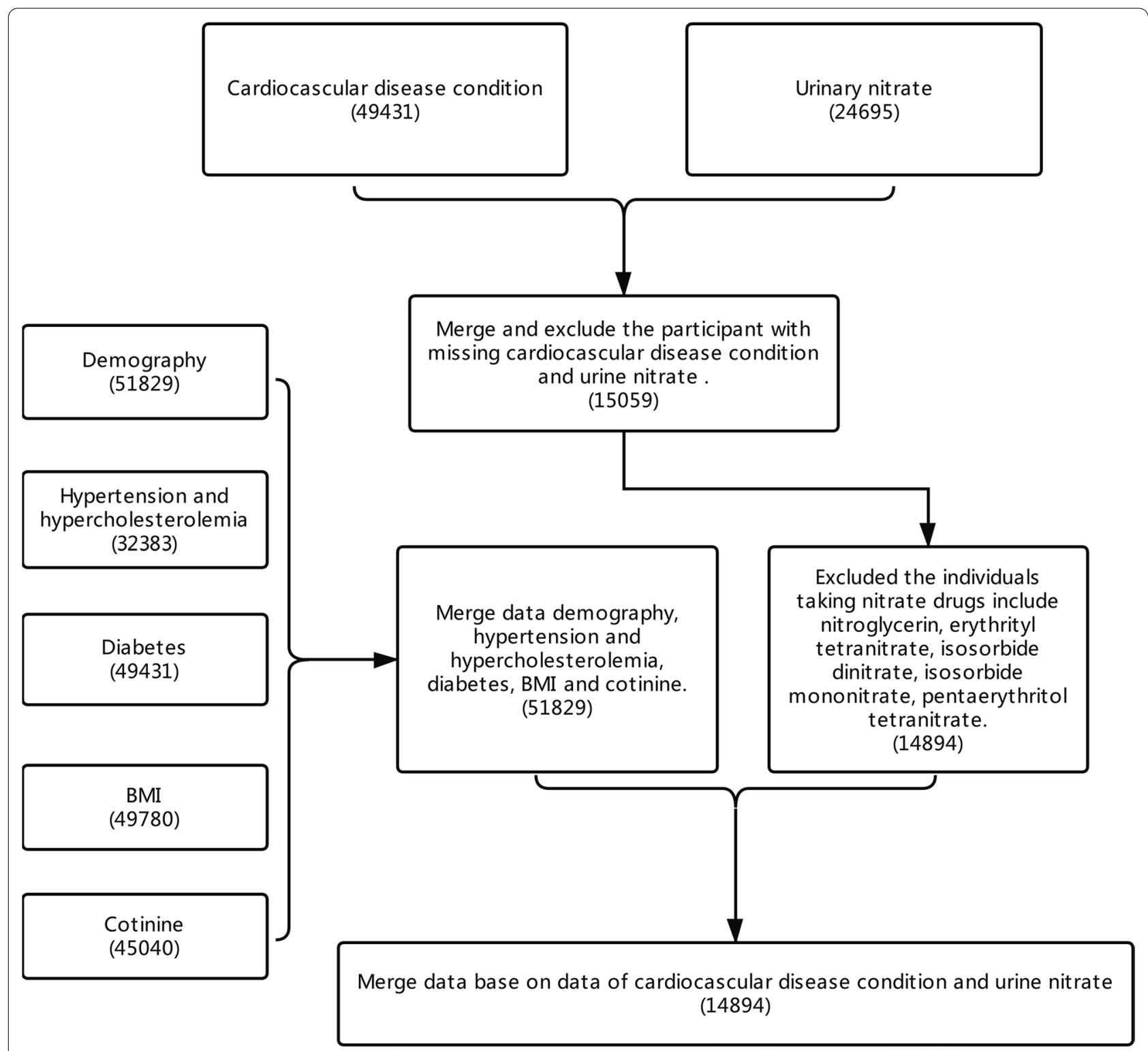

Fig. 1 Participant flowchart

atherosclerosis (ATH-er-o-skler-O-sis). Blocked blood vessels to the heart can cause chest pain or a heart attack.

Interviewer If the respondent reports chest pain, probe if a doctor told them that they had blocked blood vessels or coronary heart disease.

Angina (Angina Pectoris) (AN-ji-na or an-JI-na). Angina is chest pain or discomfort that occurs when the heart does not get enough blood.
Interviewer If the respondent reports chest pain, probe if a doctor told them that they had blocked blood vessels or angina.

Heart attack (Myocardial Infarction) A heart attack happens when there is narrowing of a blood vessel that supplies the heart. A blood clot can form and suddenly cut off the blood supply to the heart muscle. This damage causes crushing chest pain that may also be felt in the arms or neck. There can also be nausea, sweating, or shortness of breath. 


\section{Covariates}

A wide range of socio-demographic variables and medical histories were collected in NHANES including sex, age (years), ethnicity (Mexican American, Other Hispanic, Non-Hispanic White, Non-Hispanic Black and Other Race-Including Multi-Racial), BMI (Individuals were divided as overweight if their BMI value ranging from 25 to $30 \mathrm{~kg} / \mathrm{m}^{2}$, and obese if their BMI $\geq 30 \mathrm{~kg} / \mathrm{m}^{2}$ on the basis of the World Health Organization (WHO) standards), serum cotinine (non-smoker defined as serum cotinine $\leq 10 \mathrm{ng} / \mathrm{mL}$ and smoker defined as serum cotinine $>10 \mathrm{ng} / \mathrm{mL}$ ) [17], poverty income ratio (PIR) [poverty: PIR $\leq 1$, beyond the poverty threshold: PIR >1], hypertension, hypercholesterolemia and diabetes history. The history of hypertension, hypercholesterolemia and diabetes were defined as participants confirmed yes to the questions "Have you ever been told by a doctor or other health professional that you had hypertension, also called high blood pressure?", "Have you ever been told by a doctor or other health professional that your blood cholesterol level was high?" and "Have you ever been told by a doctor or health professional that you have diabetes or sugar diabetes?".

\section{Statistical analyses}

All statistical analysis was on the $\mathrm{R}$ software (version 3.2.3). Logistic regression models with were used to examine the associations between urinary nitrate and CVDs by using the "survey" package. Each analysis used sample weights to estimate representatives of the US population. Logistic regression models with complex sample were applied to test the associations between CVDs and urinary nitrate adjusted by covariates (age, sex, ethnicity, serum cotinine, BMI, PIR, hypertension, hypercholesterolemia and diabetes history). We would perform logistic analysis twice, taking urinary nitrate as continuous variables and categorical factors respectively. In the model which used continuous urinary nitrate, urinary nitrate was normalized for creatinine as follows: urinary nitrate concentration $(\mathrm{ng} / \mathrm{mL}) /($ urinary creatinine $(m g / d L) / 100)=\mu g$ nitrate $/ g$ creatinine. Then normalized nitrate was transferred by the natural log transformation for the significant deviation from the normal distribution. In the model using categorical urinary nitrate, the level of urinary nitrates was divided into quartiles $(\mathrm{Q} 1: \leq 26,100$; Q2: 26,100-45,000; Q3: 45,000-70,600; Q4: > 70,600) by the interquartile. Both models were applied for the stratified analysis by genders and age groups (younger people age 20-60 years and older people age over 65 years) between CVDs and nitrate. All significance tests were two-sided with significant threshold of 0.05 .

\section{Results}

General demographic information

14,894 participants were included in this study from 5 NHANES surveys. Demographic characteristics of all participants and different urinary nitrate groups were shown in Table 1. Genders had a balance of distribution which female accounted for $51.36 \%$. The prevalence of hypertension, hypercholesterolemia and diabetes were $32.86 \%$ (4883), 41.21\% (4415) and $11.10 \%$ (1626) respectively. Participants with any of the congestive heart failure, coronary heart disease, angina and myocardial infarction had lower urinary nitrate levels, demonstrated in Additional file 1: Table S1.

\section{Association between urinary nitrate and CVDs}

To explore whether urinary nitrate levels were associated with any CVDs, logistic regression methods were used by conducting univariable and multivariable analyses. Pronounced association were found between urinary nitrate levels and prevalent congestive heart failure, coronary heart disease, angina pectoris and myocardial infarction in the univariable logistic analysis (all $P<0.001$ ) (Tables 2, 3 ). After adjusting related covariates, the multivariable logistic analysis showed that the significant association only existed between urinary nitrate and occurrence of congestive heart failure $(\mathrm{OR}=0.651,95 \% \mathrm{CI} 0.507-0.838$, $P<0.001$ ), details were displayed in Table 2. Furthermore, the concentration of urinary nitrate was divided into quartiles (Q1, Q2, Q3 and Q4) according to the interquartile. Compared to Q1 which was reference group, the Q2, Q3 and Q4 had pronounced negative correlation with congestive heart failure $(\mathrm{OR}=0.633,95 \% \mathrm{CI} 0.403$, 0.994), (OR=0.425, 95\% CI 0.230, 0.783), (OR=0.375, 95\% CI 0.210, 0.661), respectively. Trend test showed statistical significance $(P<0.001)$ in Table 3.

\section{Stratification analysis}

In view of the different distribution of congestive heart failure in various age and gender groups, further stratification logistic analyses were performed. Corresponding results were listed in Table 4 . In the 20-60 years group, urinary nitrate levels were associated with congestive heart failure in a dose-dependent manner $(P<0.001)$. Compared with Q1 reference group, risk of having congestive heart failure in the Q3 group $(\mathrm{OR}=0.224,95 \% \mathrm{CI}$ $0.082,0.608)$ and $\mathrm{Q} 4$ group $(\mathrm{OR}=0.195,95 \%$ CI 0.071 , 0.534 ) were significantly lower. It was found that urinary nitrate levels had significantly negative correlation with congestive heart failure in $>60$ years group $(P=0.011)$. Q4 group had lower congestive heart failure than Q1 group $(\mathrm{OR}=0.485,95 \% \mathrm{CI} 0.251,0.936)$. In addition, regardless of genders, the inverse relationship between 
Table 1 Baseline characteristics of all study participants divided by urinary nitrate groups

\begin{tabular}{|c|c|c|c|c|c|c|}
\hline \multirow[t]{2}{*}{ Variables } & \multirow{2}{*}{$\begin{array}{l}\text { All participants, } \\
n=14,894\end{array}$} & \multicolumn{4}{|c|}{ Urinary nitrate $(\mathrm{ng} / \mathrm{mL})^{a}$} & \multirow[t]{2}{*}{$P$} \\
\hline & & $\mathrm{Q} 1, \mathrm{n}=3714$ & $Q 2, n=3736$ & $Q 3, n=3708$ & $Q 4, n=3736$ & \\
\hline Age & $48.67(18.00)$ & $53.29(18.48)$ & $50.09(18.10)$ & $47.11(17.66)$ & $44.22(16.44)$ & $<0.001$ \\
\hline \multicolumn{6}{|l|}{ Gender } & $<0.001$ \\
\hline Male (N, \%) & $7245(48.64)$ & $1415(38.10)$ & $1761(47.14)$ & 2002 (53.99) & $2067(55.33)$ & \\
\hline Female (N, \%) & $7649(51.36)$ & $2299(61.90)$ & 1975 (52.86) & $1706(46.01)$ & $1669(44.67)$ & \\
\hline \multicolumn{6}{|l|}{ Race (N, \%) } & $<0.001$ \\
\hline Mexican American & $2668(17.91)$ & $614(16.53)$ & $614(18.09)$ & $686(18.50)$ & $692(18.52)$ & \\
\hline Other Hispanic & $1175(7.89)$ & $286(7.70)$ & $293(7.84)$ & $306(8.25)$ & $290(7.76)$ & \\
\hline Non-Hispanic White & $7011(47.07)$ & 1916 (51.59) & $1740(46.57)$ & $1653(44.58)$ & $1702(45.56)$ & \\
\hline Non-Hispanic Black & $3184(21.38)$ & $710(19.22)$ & $846(22.64)$ & $862(23.25)$ & $76620.50)$ & \\
\hline $\begin{array}{l}\text { Other race_-including } \\
\text { multi-racial }\end{array}$ & $856(5.75)$ & $188(5.06)$ & $181(4.84)$ & $201(5.42)$ & $286(7.66)$ & \\
\hline \multicolumn{6}{|l|}{$\operatorname{PIR}(N, \%)$} & 0.276 \\
\hline$\leq 1$ & $2719(19.74)$ & $660(19.32)$ & $657(19.02)$ & $671(19.51)$ & $731(21.12)$ & \\
\hline$>1$ & $11,052(80.26)$ & $2757(80.68)$ & 2797 (80.98) & 2786 (80.49) & $2730(78.88)$ & \\
\hline \multicolumn{6}{|l|}{ Cotinine $(\mathrm{N}, \%)$} & $<0.001$ \\
\hline \multicolumn{7}{|l|}{$\leq 0.01$} \\
\hline $0.01-10$ & $10,547(74.44)$ & $2900(82.18)$ & $2749(77.22)$ & $2585(73.31)$ & $2313(65.10)$ & \\
\hline$>10$ & $3621(25.56)$ & $629(17.82)$ & $811(22.78)$ & $941(26.69)$ & $1240(34.90)$ & \\
\hline \multicolumn{6}{|l|}{ BMI $(\mathrm{N}, \%)$} & $<0.001$ \\
\hline$<25$ & $4448(30.33)$ & $1231(33.91)$ & $1118(30.31)$ & $979(26.81)$ & $1120(30.33)$ & \\
\hline $25-30$ & $5019(34.23)$ & $1228(33.83)$ & $1268(34.37)$ & $1289(35.30)$ & $1234(33.41)$ & \\
\hline$>30$ & $5197(35.44)$ & $1171(32.26)$ & $1303(35.32)$ & $1384(37.90)$ & $1339(36.26)$ & \\
\hline \multicolumn{6}{|l|}{ Hypertension (N, \%) } & $<0.001$ \\
\hline No & $9977(67.14)$ & $2208(59.53)$ & $2397(64.31)$ & $2595(70.23)$ & $2777(74.47)$ & \\
\hline Yes & $4883(32.86)$ & $1501(40.47)$ & $1330(35.69)$ & $1100(29.77)$ & $952(25.53)$ & \\
\hline \multicolumn{6}{|c|}{ Hypercholesterolemia (N, \%) } & $<0.001$ \\
\hline No & $6298(58.79)$ & $1618(56.75)$ & $1579(56.92)$ & $1569(60.30)$ & $1532(61.63)$ & \\
\hline Yes & $4415(41.21)$ & $1233(43.25)$ & $1195(43.08)$ & $1033(39.70)$ & $954(38.37)$ & \\
\hline \multicolumn{6}{|l|}{ Diabetes (N, \%) } & $<0.001$ \\
\hline No & $13,017(88.90)$ & $3118(85.31)$ & $3229(87.91)$ & $3265(89.80)$ & 3405 (92.55) & \\
\hline Yes & $1626(11.10)$ & $537(14.69)$ & $444(12.09)$ & $371(10.20)$ & $274(7.45)$ & \\
\hline
\end{tabular}

PIR poverty impact ratio, $B M I$ body mass index, Cotinine the predominate metabolite of nicotine

a Urine nitrate was divided to four levels by quartile (Q1: $\leq 26,100 ; \mathrm{Q} 2: 26,100-45,000 ; \mathrm{Q} 3: 45,000-70,600 ; \mathrm{Q} 4:>70,600)$

Table 2 Logistic regression results for relationship between urinary nitrate (log transformation) and various cardiovascular diseases

\begin{tabular}{|c|c|c|c|c|}
\hline & OR $(95 \% C l)^{a}$ & $P$ & OR $(95 \% \mathrm{Cl})^{\mathrm{b}}$ & $P$ \\
\hline Congestive heart failure & $0.980(0.976,0.984)$ & $<0.001$ & $0.651(0.507,0.838)$ & $<0.001$ \\
\hline Coronary heart disease & $0.989(0.985,0.993)$ & $<0.001$ & $1.052(0.776,1.426)$ & 0.745 \\
\hline Angina pectoris & $0.992(0.988,0.996)$ & $<0.001$ & $0.894(0.720,1.110)$ & 0.309 \\
\hline Myocardial infarction & $0.990(0.985,0.994)$ & $<0.001$ & $1.076(0.869,1.331)$ & 0.503 \\
\hline
\end{tabular}

a Model was not adjusted by any covariate

b Model was adjusted by age, gender, race/ethnicity, poverty income ratio, cotinine, BMI, hypertension, hypercholesterolemia and diabetes (poverty income ratio: $\mathrm{Q} 1: \leq 1, \mathrm{Q} 2:>1$; cotinine: Q1: $\leq 0.01, \mathrm{Q} 2: 0.01-10, \mathrm{Q} 3:>10 ; \mathrm{BMI}: \mathrm{Q} 1:<25 ; \mathrm{Q} 2: 25-30 ; \mathrm{Q} 3:>30)$ 
Table 3 Logistic regression results for relationship between urinary nitrate levels and various cardiovascular diseases

\begin{tabular}{|c|c|c|c|c|}
\hline & OR $(95 \% \mathrm{Cl})^{\mathrm{a}}$ & $P$ for trend & OR $(95 \% \mathrm{Cl})^{\mathrm{b}}$ & $P$ for trend \\
\hline \multicolumn{5}{|c|}{ Congestive heart failure } \\
\hline Q1 & Ref & \multirow[t]{4}{*}{$<0.001$} & Ref & \multirow[t]{4}{*}{$<0.001$} \\
\hline Q2 & $0.978(0.971,0.986)$ & & $\begin{array}{l}0.633(0.403 \\
0.994)\end{array}$ & \\
\hline Q3 & $\begin{array}{l}0.970(0.964 \\
0.977)\end{array}$ & & $\begin{array}{l}0.425(0.230 \\
0.783)\end{array}$ & \\
\hline Q4 & $\begin{array}{l}0.967(0.960 \\
0.973)\end{array}$ & & $\begin{array}{l}0.375(0.210 \\
0.661)\end{array}$ & \\
\hline \multicolumn{5}{|c|}{ Coronary heart disease } \\
\hline Q1 & Ref & \multirow[t]{4}{*}{$<0.001$} & Ref & \multirow[t]{4}{*}{0.567} \\
\hline Q2 & $\begin{array}{l}1.000(0.992, \\
1.008)\end{array}$ & & $\begin{array}{l}0.981(0.618 \\
1.555)\end{array}$ & \\
\hline Q3 & $\begin{array}{l}0.986(0.978 \\
0.993)\end{array}$ & & $\begin{array}{l}0.632(0.365 \\
1.094)\end{array}$ & \\
\hline Q4 & $\begin{array}{l}0.983(0.975 \\
0.991)\end{array}$ & & $\begin{array}{l}1.003(0.586, \\
1.717)\end{array}$ & \\
\hline \multicolumn{5}{|c|}{ Angina pectoris } \\
\hline Q1 & Ref & \multirow[t]{4}{*}{$<0.001$} & Ref & \multirow[t]{4}{*}{0.745} \\
\hline Q2 & $\begin{array}{l}0.994(0.988 \\
1.001)\end{array}$ & & $\begin{array}{l}0.800(0.446 \\
1.437)\end{array}$ & \\
\hline Q3 & $\begin{array}{l}0.990(0.984 \\
0.996)\end{array}$ & & $\begin{array}{l}0.462(0.252 \\
0.846)\end{array}$ & \\
\hline Q4 & $\begin{array}{l}0.989(0.982 \\
0.995)\end{array}$ & & $\begin{array}{l}0.697(0.372 \\
1.303)\end{array}$ & \\
\hline \multicolumn{5}{|c|}{ Myocardial infarction } \\
\hline Q1 & Ref & \multirow[t]{4}{*}{$<0.001$} & Ref & \multirow[t]{4}{*}{0.617} \\
\hline Q2 & $\begin{array}{l}0.992(0.984 \\
0.983)\end{array}$ & & $\begin{array}{l}0.785(0.499 \\
1.233)\end{array}$ & \\
\hline Q3 & $\begin{array}{l}0.984(0.976 \\
0.992)\end{array}$ & & $\begin{array}{l}0.751(0.437 \\
1.288)\end{array}$ & \\
\hline Q4 & $\begin{array}{l}0.983(0.975 \\
0.991)\end{array}$ & & $\begin{array}{l}0.913(0.535 \\
1.558)\end{array}$ & \\
\hline
\end{tabular}

a Model was not adjusted by any covariate

b Model was adjusted by age, gender, race/ethnicity, poverty income ratio, cotinine, BMI, hypertension, hypercholesterolemia and diabetes. (poverty income ratio: Q1: $\leq 1, \mathrm{Q} 2:>1$; cotinine: $\mathrm{Q} 1: \leq 0.01, \mathrm{Q} 2: 0.01-10, \mathrm{Q} 3:>10$; $\mathrm{BMI}$ : $\mathrm{Q} 1:<25 ; \mathrm{Q} 2: 25-30 ; \mathrm{Q} 3:>30)$ urinary nitrate and congestive heart failure still existed in both male and female groups $(P=0.009, P=0.004$, respectively). There were no connections between urinary nitrate and coronary heart disease, angina in each gender and age groups. Furthermore, we performed age stratification in each sex group, as we can see from Table 5, the significant association existed in every subgroup except in $>60$ years female subgroup.

\section{Discussion}

Higher urinary nitrate was associated with lower prevalence of congestive heart failure from this cross-sectional study. Subjects with congestive heart failure had significant lower urinary nitrate levels. Nitrate and nitrite, previously known as unnecessary residues in the food chain, have potentially carcinogenic effects, especially positively related to gastric cancer [18]. Nowadays, it is widely recognized that nitrite and nitrate are important reservoirs of $\mathrm{NO}$ and crucial for maintenance of NO physiological levels [5]. Dietary nitrate can affect NO in the circulation in a dose-dependent manner by increasing the levels of nitrite, NO, and related nitroso compounds [19-22]. Through the classic L-arginine-NO-synthase pathway, inert nitrogen anion circulates in vivo to form $\mathrm{NO}$ [23].

After adjusting the involved covariates, the negative correlation between CVDs and urinary nitrate only existed in patients with congestive heart failure. Worldwide, heart failure is a major public health problem with a total number more than 23 million and still rising [24]. Heart failure is the terminal conditions of many heart diseases, for instance, ischemic heart disease, coronary artery disease and atrial fibrillation. This disease has tremendous undesirable consequences which can lower the quality of life and even lead to death [25]. Numerous human intervention studies have investigated the effects of dietary nitrate on vascular health $[3,13,26$, 27]. These studies have shown that increased nitrate intake can improve vasorelaxation [27], lower blood pressure [2] and improve function of endothelium [4], which

Table 4 Logistic regression results for relationship between urinary nitrate levels and congestive heart failure stratified by age groups and genders respectively

\begin{tabular}{|c|c|c|c|c|}
\hline Urinary nitrate $^{a}$ & $20-60$ year OR $(95 \% \mathrm{Cl})$ & $60+$ year OR $(95 \% \mathrm{Cl})$ & Male OR $(95 \% \mathrm{Cl})$ & Female OR $(95 \% \mathrm{Cl})$ \\
\hline Q1 & Ref & Ref & Ref & Ref \\
\hline Q2 & $0.621(0.287,1.343)$ & $0.621(0.359,1.077)$ & $0.629(0.343,1.152)$ & $0.690(0.354,1.344)$ \\
\hline Q3 & $0.224(0.082,0.608)$ & $0.508(0.255,1.011)$ & $0.356(0.138,0.915)$ & $0.600(0.290,1.242)$ \\
\hline Q4 & $0.195(0.071,0.534)$ & $0.485(0.251,0.936)$ & $0.441(0.217,0.899)$ & $0.201(0.076,0.530)$ \\
\hline$P$ for trend & $<0.001$ & 0.011 & 0.009 & 0.004 \\
\hline
\end{tabular}

All models were adjusted by age, gender, race/ethnicity, poverty income ratio, cotinine, BMI, hypertension, hypercholesterolemia and diabetes (poverty income ratio: Q1: $\leq 1, \mathrm{Q} 2:>1$; cotinine: Q1: $\leq 0.01, \mathrm{Q} 2: 0.01-10, \mathrm{Q} 3:>10 ; \mathrm{BMI}: \mathrm{Q} 1:<25 ; \mathrm{Q} 2: 25-30 ; \mathrm{Q} 3:>30)$

a Urinary nitrate was divided to four levels by quartile (Q1: $\leq 26,100 ; \mathrm{Q} 2: 26,100-45,000 ; \mathrm{Q} 3: 45,000-70,600 ; \mathrm{Q} 4:>70,600$ ) 
Table 5 Logistic regression results for relationship between urinary nitrate levels and congestive heart failure stratified by age groups and genders

\begin{tabular}{cllll}
\hline & Male & & Female & \\
\hline Urinary nitrate $^{\mathrm{a}}$ & $20-60$ & $60+$ & $20-60$ & $60+$ \\
Q1 & Ref & Ref & Ref & Ref \\
Q2 & $0.829(0.317,2.166)$ & $0.531(0.249,1.135)$ & $0.344(0.099,1.186)$ & $0.807(0.376,1.703)$ \\
Q3 & $0.138(0.033,0.582)$ & $0.407(0.160,1.033)$ & $0.507(0.118,2.171)$ & $0.672(0.287,1.573)$ \\
Q4 & $0.262(0.074,0.925)$ & $0.494(0.214,1.140)$ & $0.058(0.006,0.519)$ & $0.291(0.099,0.858)$ \\
Pfor trend & 0.008 & 0.049 & 0.024 & 0.053 \\
\hline
\end{tabular}

All models were adjusted by age, gender, race/ethnicity, poverty income ratio, cotinine, BMI, hypertension, hypercholesterolemia and diabetes (poverty income ratio: $\mathrm{Q} 1: \leq 1, \mathrm{Q} 2:>1$; cotinine: Q1: $\leq 0.01, \mathrm{Q} 2: 0.01-10, \mathrm{Q} 3:>10 ; \mathrm{BMI}: \mathrm{Q} 1:<25 ; \mathrm{Q} 2: 25-30 ; \mathrm{Q} 3:>30)$

a Urinary nitrate was divided to four levels by quartile (Q1: $\leq 26,100 ; \mathrm{Q} 2: 26,100-45,000 ; \mathrm{Q} 3: 45,000-70,600 ; \mathrm{Q} 4:>70,600$ )

eventually resulted in lower death risk of atherosclerotic vascular disease (ASVD) [10]. NO is an endotheliumderived relaxing factor (EDRF) endogenously biosynthesized from L-arginine, oxygen, and Nicotinamide Adenine Dinucleotide Phosphate (NADPH) via various nitric oxide synthase (NOS) enzymes [28]. The vascular endothelium (inner lining) uses NO to give a signal of making surrounding smooth muscle relaxing, thus resulting in the process of vasodilation and increasing blood flow $[29,30]$. In an intervention study, patients with systolic heart failure were well-tolerated for acute dietary $\mathrm{NO}_{3}{ }^{-}$intake, and had enhanced $\mathrm{NO}$ bioavailability and exercise capacity [31]. In addition, $\mathrm{NO}_{3}{ }^{-}$increased vasodilatory ability, cardiac output reserves and reduced arterial wave reflections in heart failure patients with Preserved Ejection Fraction [32].

About $65-70 \%$ of nitrate is excreted in urine in the $24 \mathrm{~h}$ and less than $1 \%$ is excreted into feces [33]. Urinary nitrate levels are generally considered as appropriate biomarkers for assessing chronic exposure. Nitrate in blood is also a good marker of human exposure; however, it is more susceptible to recent exposures. Therefore, urinary nitrate can represent stable and real nitrate concentration in human body [34-36]. At present, there are lots of researches at home and abroad focusing on the relationship between urinary nitrate and other diseases. For example, the decrease in urinary nitrate concentration in neonates with persistent pulmonary hypertension (PPHN) implied a role of NO in the pathogenesis of PPHN [37]. Furthermore, from the 2005-2006 National Health and Nutrition Examination Survey, Ko et al. [38] found the inverse association between urinary nitrate and thiocyanate concentrations in U.S. Adults.

Our data suggested that the remarkable relationships was existed in different gender and age groups. From self-reported data obtained from 2003 to 2006 National Health and Nutrition Examination Survey, the prevalence of heart failure increased with age, and males were higher than females. There are differences in gene expression and physiology between men and women, so that gender has a broad impact on human biology and disease development [39]. Studies have indicated that estrogen plays a protective role in the maintenance of cardiovascular health among females, reducing the occurrence of CVDs, thereby reducing the CVDs mortality rate in women. In our study, the association between urinary nitrate levels and congestive heart failure was no longer meaningful in $>60$ year female subgroup. This could be explained by that the decrease of estrogen secretion in postmenopausal women [40].

Other studies had evaluated the relationship between nitrate and atherosclerotic vascular disease (ASVD), carotid atherosclerosis and ischemic cerebrovascular disease [10]. However, it is worth mentioning that our study comprehensively and systematically explored the association of urinary nitrate with various kinds of CVDs based on large samples from well-designed database. There are still some limitations in this study. For instance, exposure misclassification would exist because of imperfect single measurements of urinary nitrate as markers of chronic exposure. In addition, the cross-sectional study might hinder the real interpretation of causality from the results. The longitudinal study design is in necessity to understand the true association between nitrate and congestive heart failure. Besides, the definitions of these CVDs are based on the self-reported information in the face-to-face interview, there may be some bias which affected the results to some extent. However, previous scholars also do researches on the CVDs and other diseases based on the self-reported information from the NAHENS $[41,42]$. The study design of NAHENS is reasonable, and investigators have received good training. When conducting the interview, a computer-aided investigation system can help participants easily understanding health-related questions. For the cardiovascular 
disease outcomes in this study, there are detailed problem description and explanation for each question. Based on the conclusion of medical diagnosis recall, the results are relatively reliable.

\section{Conclusions}

Higher urinary nitrate was associated with lower prevalence of congestive heart failure and these significant results were still existed in most gender and age groups. This can remind us that raised intake of dietary nitrate may help resist the occurrence of congestive heart failure in particular populations.

\section{Supplementary information}

Supplementary information accompanies this paper at https://doi. org/10.1186/s12872-020-01790-w.

Additional file 1: Table S1. The urinary nitrate level of various cardiovascular diseases.

\section{Abbreviations}

CVD: Cardiovascular disease; Cl: Confidence interval; OR: Odds ratio; NHANES National Health and Nutrition Examination Surveys; NO: Nitric oxide; BMI: Body mass index; WHO: World Health Organization; PIR: Poverty income ratio; ASVD: Atherosclerotic vascular disease.

\section{Acknowledgements}

We would like to thank Dr Xiang Huo, for his valuable assists on statistical analysis and general aspects.

\section{Authors' contributions}

ZW and TT contributed to the hypothesis development and to the manuscript preparation; WM, ZW, and WG contributed to the study design; WM and TT were responsible for the data analysis; NS contributed to the data interpretation and manuscript revision. All authors read and approved the final manuscript.

\section{Funding}

This work was supported by the National Science Foundation of China [Grant No. 81871151]; the National Science Foundation of China [Grant No. 81572262]; Jiangsu Province's Key Provincial Talents Program [Grant No. ZDRCA2016009]; Jiangsu Province's Key Provincial Talents Program [Grant No. ZDRCA2016028]; 333 high class Talented Man Project [Grant No. BRA2015471]; 333 high class Talented Man Project [Grant No. BRA2016516] and the Nature Science Foundation of the Jiangsu Higher Education Institution of China [Grant No. 18KJB320006]

\section{Availability of data and materials}

The NHANES database is available at: https://www.cdc.gov/nchs/nhanes/ about_nhanes.htm. The datasets used and/or analyzed during the current study are available from the corresponding author on reasonable request.

\section{Ethics approval and consent to participate}

An ethics statement was not required for this work. Data used in the analysis were anonymized. The NHANES database was open to the public and did not require any ethical or administrative permission.

\section{Consent for publication}

Not applicable.

\section{Competing interests}

The authors declare no conflict of interest.

\section{Author details}

${ }^{1}$ The First Affiliated Hospital of Nanjing Medical University, Jiangsu Province Hospital, Nanjing 210029, Jiangsu, China. ${ }^{2}$ Institute of Food Safety and Assessment, Jiangsu Provincial Center for Disease Control and Prevention, Nanjing 210009, China.

Received: 15 August 2020 Accepted: 19 November 2020

Published online: 25 November 2020

\section{References}

1. Mensinga TT, Speijers GJ, Meulenbelt J. Health implications of exposure to environmental nitrogenous compounds. Toxicol Rev. 2003;22(1):41-51.

2. Siervo M, Lara J, Ogbonmwan I, Mathers JC. Inorganic nitrate and beetroot juice supplementation reduces blood pressure in adults: a systematic review and meta-analysis. J Nutr. 2013;143(6):818-26.

3. Bondonno CP, Croft KD, Ward N, Considine MJ, Hodgson JM. Dietary flavonoids and nitrate: effects on nitric oxide and vascular function. Nutr Rev. 2015;73(4):216-35.

4. Lara J, Ashor AW, Oggioni C, Ahluwalia A, Mathers JC, Siervo M. Effects of inorganic nitrate and beetroot supplementation on endothelial function: a systematic review and meta-analysis. Eur J Nutr. 2016;55(2):451-9.

5. Rajapakse NW, Nanayakkara S, Kaye DM. Pathogenesis and treatment of the cardiorenal syndrome: implications of L-arginine-nitric oxide pathway impairment. Pharmacol Ther. 2015;154:1-12.

6. Weitzberg E, Lundberg JO. Novel aspects of dietary nitrate and human health. Annu Rev Nutr. 2013;33:129-59.

7. McKnight GM, Smith LM, Drummond RS, Duncan CW, Golden M, Benjamin N. Chemical synthesis of nitric oxide in the stomach from dietary nitrate in humans. Gut. 1997;40(2):211-4.

8. Lundberg JO, Weitzberg E, Lundberg JM, Alving K. Intragastric nitric oxide production in humans: measurements in expelled air. Gut. 1994;35(11):1543-6.

9. WHO: World Heart Day 2017, vol 2019; 2019.

10. Blekkenhorst LC, Bondonno CP, Lewis JR, Devine A, Woodman RJ, Croft KD, Lim WH, Wong G, Beilin LJ, Prince RL, et al. Association of dietary nitrate with atherosclerotic vascular disease mortality: a prospective cohort study of older adult women. Am J Clin Nutr. 2017;106(1):207-16.

11. Bondonno $C P$, Blekkenhorst LC, Prince RL, Ivey $K L$, Lewis JR, Devine A, Woodman RJ, Lundberg JO, Croft KD, Thompson PL, et al. Association of vegetable nitrate intake with carotid atherosclerosis and ischemic cerebrovascular disease in older women. Stroke. 2017;48(7):1724-9.

12. Larsen FJ, Ekblom B, Sahlin K, Lundberg JO, Weitzberg E. Effects of dietary nitrate on blood pressure in healthy volunteers. N Engl J Med. 2006:355(26):2792-3.

13. Webb AJ, Patel N, Loukogeorgakis S, Okorie M, Aboud Z, Misra S, Rashid R, Miall P, Deanfield J, Benjamin N, et al. Acute blood pressure lowering, vasoprotective, and antiplatelet properties of dietary nitrate via bioconversion to nitrite. Hypertension. 2008;51(3):784-90.

14. Vita JA, Treasure CB, Nabel EG, McLenachan JM, Fish RD, Yeung AC, Vekshtein VI, Selwyn AP, Ganz P. Coronary vasomotor response to acetylcholine relates to risk factors for coronary artery disease. Circulation. 1990;81(2):491-7.

15. Johnson CL, Paulose-Ram R, Ogden CL, Carroll MD, Kruszon-Moran D, Dohrmann SM, Curtin LR: National Health and Nutrition Examination Survey: analytic guidelines, 1999-2010. In: Vital and health statistics. Series 2, Data evaluation and methods research; 2013(161). p. 1-24.

16. Valentin-Blasini L, Mauldin JP, Maple D, Blount BC. Analysis of perchlorate in human urine using ion chromatography and electrospray tandem mass spectrometry. Anal Chem. 2005;77(8):2475-81.

17. Jain RB. Impact of pregnancy and other factors on the levels of urinary perchlorate, thiocyanate, and nitrate among females aged 15-44 years: data from National Health and Nutrition Examination Survey: 2003-2008. Chemosphere. 2013;91(7):882-7.

18. Joossens JV, Hill MJ, Elliott P, Stamler R, Lesaffre E, Dyer A, Nichols R, Kesteloot $\mathrm{H}$. Dietary salt, nitrate and stomach cancer mortality in 24 countries. European Cancer Prevention (ECP) and the INTERSALT Cooperative Research Group. Int J Epidemiol. 1996;25(3):494-504. 
19. Lundberg JO, Govoni M. Inorganic nitrate is a possible source for systemic generation of nitric oxide. Free Radical Biol Med. 2004;37(3):395-400.

20. Govoni M, Jansson EA, Weitzberg E, Lundberg JO. The increase in plasma nitrite after a dietary nitrate load is markedly attenuated by an antibacterial mouthwash. Nitric Oxide Biol Chem. 2008;19(4):333-7.

21. Petersson J, Carlstr MM, Schreiber O, Phillipson M, Christoffersson G, Roos S, Jansson EA, Persson AE, Lundberg JO, et al. Gastroprotective and blood pressure lowering effects of dietary nitrate are abolished by an antiseptic mouthwash. Free Radic Biol Med. 2009;46(8):1068-75.

22. Bondonno CP, Croft KD, Puddey IB, Considine MJ, Yang X, Ward NC, Hodgson JM. Nitrate causes a dose-dependent augmentation of nitric oxide status in healthy women. Food Funct. 2012;3(5):522-7.

23. Lundberg JO, Weitzberg E, Gladwin MT. The nitrate-nitrite-nitric oxide pathway in physiology and therapeutics. Nat Rev Drug Discov. 2008;7(2):156-67.

24. Bui AL, Horwich TB, Fonarow GC. Epidemiology and risk profile of heart failure. Nat Rev Cardiol. 2011;8(1):30-41.

25. Havranek EP, Masoudi FA, Westfall KA, Wolfe P, Ordin DL, Krumholz HM Spectrum of heart failure in older patients: results from the National Heart Failure project. Am Heart J. 2002;143(3):412-7.

26. Kapil V, Khambata RS, Robertson A, Caulfield MJ, Ahluwalia A. Dietary nitrate provides sustained blood pressure lowering in hypertensive patients: a randomized, phase 2 , double-blind, placebo-controlled study. Hypertension. 2015;65(2):320-7.

27. Falls R, Seman M, Braat S, Sortino J, Allen JD, Neil CJ. Inorganic nitrate as a treatment for acute heart failure: a protocol for a single center, randomized, double-blind, placebo-controlled pilot and feasibility study. J Transl Med. 2017;15(1):172.

28. Palmer RM, Ashton DS, Moncada S. Vascular endothelial cells synthesize nitric oxide from L-arginine. Nature. 1988;333(6174):664-6.

29. Ignarro LJ, Buga GM, Wood KS, Byrns RE, Chaudhuri G. Endotheliumderived relaxing factor produced and released from artery and vein is nitric oxide. Proc Natl Acad Sci USA. 1987;84(24):9265-9.

30. Palmer RM, Ferrige AG, Moncada S. Nitric oxide release accounts for the biological activity of endothelium-derived relaxing factor. Nature. 1987;327(6122):524-6.

31. Coggan AR, Leibowitz JL, Spearie CA, Kadkhodayan A, Thomas DP, Ramamurthy S, Mahmood K, Park S, Waller S, Farmer M, et al. Acute dietary nitrate intake improves muscle contractile function in patients with heart failure: a double-blind, Placebo-controlled, randomized trial. Circ Heart Fail. 2015;8(5):914-20

32. Zamani P, Rawat D, Shiva-Kumar P, Geraci S, Bhuva R, Konda P, Doulias PT, Ischiropoulos H, Townsend RR, Margulies KB, et al. Effect of inorganic nitrate on exercise capacity in heart failure with preserved ejection fraction. Circulation. 2015;131(4):371-80.

33. Pannala AS, Mani AR, Spencer JP, Skinner V, Bruckdorfer KR, Moore $K P$, Rice-Evans CA. The effect of dietary nitrate on salivary, plasma, and urinary nitrate metabolism in humans. Free Radic Biol Med. 2003;34(5):576-84.

34. Bartholomew B, Hill MJ. The pharmacology of dietary nitrate and the origin of urinary nitrate. Food Chem Toxicol. 1984;22(10):789-95.

35. Granger DL, Hibbs JB, Broadnax LM. Urinary nitrate excretion in relation to murine macrophage activation. Influence of dietary L-arginine and oral NG-monomethyl-L-arginine. J Immunol. 1991;146(4):1294-302.

36. Oldreive C, Bradley N, Bruckdorfer R, Rice-Evans C. Lack of influence of dietary nitrate/nitrite on plasma nitrotyrosine levels measured using a competitive inhibition of binding ELISA assay. Free Radic Res. 2001;35(4):377-86.

37. Dollberg S, Warner BW, Myatt L. Urinary nitrite and nitrate concentrations in patients with idiopathic persistent pulmonary hypertension of the newborn and effect of extracorporeal membrane oxygenation. Pediatr Res. 1995;37(1):31-4.

38. Ko WC, Liu CL, Lee JJ, Liu TP, Yang PS, Hsu YC, Cheng SP. Negative association between serum parathyroid hormone levels and urinary perchlorate, nitrate, and thiocyanate concentrations in U.S. adults: the National Health and Nutrition Examination Survey 2005-2006. PLoS ONE. 2014;9(12):e115245

39. Ouyang P, Wenger NK, Taylor D, Rich-Edwards JW, Steiner M, Shaw LJ, Berga SL, Miller VM, Merz NB. Strategies and methods to study femalespecific cardiovascular health and disease: a guide for clinical scientists. Biol Sex Differ. 2016;7:19.

40. Mendelsohn ME. Protective effects of estrogen on the cardiovascular system. Am J Cardiol 2002;89(12A):12E-17E, 17E-18E.

41. Zhang $Y$, Huang $M$, Zhuang $P$, Jiao J, Chen $X$, Wang J, Wu Y. Exposure to acrylamide and the risk of cardiovascular diseases in the National Health and Nutrition Examination Survey 2003-2006. Environ Int. 2018;117:154-63.

42. Sonawane K, Chhatwal J, Deshmukh AA. Folic acid-containing dietary supplement consumption and risk of cardiovascular diseases in rheumatoid arthritis patients: NHANES 1999-2014. J Gen Intern Med. 2019;34(1):15-6.

\section{Publisher's Note}

Springer Nature remains neutral with regard to jurisdictional claims in published maps and institutional affiliations.
Ready to submit your research? Choose BMC and benefit from:

- fast, convenient online submission

- thorough peer review by experienced researchers in your field

- rapid publication on acceptance

- support for research data, including large and complex data types

- gold Open Access which fosters wider collaboration and increased citations

- maximum visibility for your research: over $100 \mathrm{M}$ website views per year

At BMC, research is always in progress.

Learn more biomedcentral.com/submissions 